\title{
Aplicação do Projeto Didático-Pedagógico “Sabão Ecológico” em uma Escola Pública de Porto Velho - RO
}

\author{
Application of Didactic and Pedagogical Project "Green Soap" in a Public School in Porto Velho - RO \\ Renato Abreu Lima', Eloísa Santana Paz ${ }^{2}$, Jaqueline Rodrigues Souza ${ }^{3}$, Andrina Guimarães Silva Braga ${ }^{4}$ \\ ' Biólogo, Pós-graduado em Gestão Ambiental, Mestre em Meio Ambiente e Doutorando em Biodiversidade e Biotecnologia, Universidade \\ Federal do Amazonas, Manaus, Brasil. \\ ${ }^{2}$ Bióloga, Desenvolve pesquisa na área de Educação e Biotecnologia Vegetal, Faculdade São Lucas, Porto Velho, Brasil. \\ ${ }^{3}$ Bióloga, Desenvolve pesquisa na área de Educação e Fitoquímica, Faculdade São Lucas, Porto Velho, Brasil. \\ ${ }^{4}$ Bióloga, Mestre em Desenvolvimento Regional e Meio Ambiente, Doutoranda em Biodiversidade e Biotecnologia, Universidade Federal \\ de Rondônia, Porto Velho, Brasil.
}

\section{Resumo}

O óleo vegetal é um resíduo de alto risco para o meio ambiente, causando sérios prejuízos quando despejado em lugares impróprios e de forma incorreta. Por exemplo, quando lançado na rede de esgoto leva à obstrução das tubulações; nos rios, além da contaminação, pode causar destruição dos seres vivos ali existentes; e o descarte no solo o impermeabiliza e contribui para o efeito estufa. Por isso há a necessidade de pesquisas com alternativas de reciclagem e coleta seletiva, que resultam em uma prática sustentável, diminuindo os prejuízos ao meio ambiente. Dessa forma, a aplicação do Projeto "Sabão Ecológico" teve por objetivo conscientizar a comunidade escolar sobre a necessidade de reutilizar o óleo de cozinha como alternativa para amenizar os impactos causados por este, quando descartado de forma incorreta no ambiente. O projeto foi aplicado em uma escola estadual da rede pública de Porto Velho, Rondônia, abrangendo as turmas do ensino médio regular. As atividades foram realizadas durante as aulas de Biologia e divididas em duas etapas, sendo a primeira de caráter teórico e a segunda prática, nesta realizou-se a produção do sabão ecológico. Conclui-se que o desenvolvimento de práticas pedagógicas diferenciadas possibilita ampliar o conhecimento, tanto da comunidade escolar quanto dos educadores, tendo como ponto principal a integração da teoria e a prática a favor da conscientização e da preservação ambiental.

Palavras-chave: Óleo; Reciclagem; Meio ambiente; Conscientização.

\begin{abstract}
Vegetable oil is a residue of high risk to the environment, causing serious damage when dumped in inappropriate places and incorrectly. For example, when released into the sewer system leads to clogging of pipes, rivers in addition to contamination, can cause destruction of living beings therein, while discarding the waterproofs the soil and contributes to the greenhouse effect. The need for research on alternative recycling and selective collection is a sustainable practice, to decrease the damage to the environment. Thus, the implementation of the Project "Green Soap" aimed to educate the school community, the need to reuse cooking oil, as an alternative to mitigate the impacts of this, when disposed of improperly in the environment. Was applied to a State School Public Network Porto Velho, Rondônia, covering the classes of regular high school. The activities were held during biology classes, and divided into two stages, the first of a theoretical and a second practice, this has made the production of ecological soap being. It is concluded that the development of differentiated teaching practices helps to widen the knowledge of both the school community, as educators, the main point the integration of theory and practice in favor of environmental awareness and preservation.
\end{abstract}

Keywords: Used oil; Recycling; Environment; Awareness. 


\section{INTRODUÇÃO}

Dentre os produtos que podem gerar efeitos ao meio ambiente, encontram-se os óleos comestíveis pós-uso, gerados diariamente em grande quantidade. Apenas a quantidade de um litro que vai para o corpo hídrico é capaz de contaminar cerca de um milhão de litros de água, equivalente ao consumo de uma pessoa em 14 anos, além de aumentar em $45 \%$ os custos no tratamento das redes de esgoto (CARVALHO, 2012; SABESP, 2011).

Muitas residências e estabelecimentos comerciais jogam o óleo usado na rede de esgoto, causando entupimento da tubulação, mau cheiro e proliferação de insetos, que se alimentam deste rejeito. Quando lançado ao solo, a consequência é o desequilíbrio ecológico, afetando lençóis freáticos e mananciais de abastecimento de água potável (ALAMINI \& BARBADO, 2008). Além da impermeabilização do solo, quando jogado a céu aberto pode contribuir para o efeito estufa, pois se trata de um composto orgânico que, ao sofrer decomposição por microorganismos, tem-se como resultado a emissão de metano na atmosfera, retendo vinte vezes mais energia que o dióxido de carbono (AZEVEDO, 2009). Outro fator observado é que ao entrar em contato com mananciais aquáticos gera graves problemas: "o óleo mais leve que a água, fica na superfície, criando uma barreira que dificulta a entrada de luz e a oxigenação da água, comprometendo assim, a base da cadeia alimentar aquática, os fitoplânctons" (ALBERICI \& PONTES, 2004).

Após várias pesquisas demonstrarem os impactos causados pelo óleo ao meio ambiente, só agora os ambientalistas concordam que não existe um modelo de descarte ideal, mas alternativas de reaproveitamento do óleo de fritura para a fabricação de biodiesel, sabão, resina para tintas, detergente, amaciante, sabonete, ração para animais, entre outros produtos (AMBIENTE EM FOCO; PORTO ALEGRE, 2012). Porém, a alternativa de reaproveitamento do óleo para fazer sabão tem sido considerada a mais simples produção tecnológica de reciclagem, fazendo com que haja um ciclo de vida desse produto (RABELO, 2008).

Rabelo \& Ferreira (2008) sugerem a coleta seletiva para óleo e gordura como melhor resultado encontrado para este tipo de material, em termos de gerenciamento de resíduos, e posteriormente a reciclagem do material recolhido. Afirmam ainda que a ação minimiza o impacto do descarte incorreto, trazendo qualidade de vida para a comunidade através das melhorias ambientais, e exercitando-os para a conscientização da sua reutilização.

Partindo do princípio de que cabe às escolas assumir o compromisso de incentivar a sociedade a refletir sobre as questões socioambientais, e participar de ações que contribuam para a melhoria da qualidade de vida de todos; a aplicação do Projeto Pedagógico "Sabão ecológico", em uma escola pública, justificou-se por instigar em toda a comunidade escolar o caráter coletivo de sua responsabilidade pela sustentabilidade local e planetária. Afinal, um dos problemas enfrentados pela sociedade moderna inclui o descarte inadequado de matérias orgânicas e inorgânicas, entre eles o óleo de cozinha.

Faz-se necessária a conscientização da sociedade para os efeitos negativos da destinação incorreta do óleo usado em residências e estabelecimentos comerciais, minimizando o impacto ambiental do resíduo. Diante disso, é necessário criar alternativas ecologicamente corretas para o destino desse produto. Dessa forma, a aplicação deste projeto teve por objetivo conscientizar a comunidade escolar da necessidade de reutilização do óleo de cozinha como alternativa de amenizar os impactos causados por este, quando descartado de forma incorreta no ambiente.

\section{METODOLOGIA}

O Projeto Sabão Ecológico foi aplicado em uma escola estadual da rede pública de Porto Velho, Rondônia, abrangendo as turmas do ensino médio regular. As atividades foram realizadas durante as aulas de Biologia, acompanhadas pela professora responsável pela disciplina nessas turmas.

As atividades foram divididas em duas etapas, sendo a primeira de caráter teórico (Figura 1) e a segunda a realização da prática (Figura 2). Na primeira etapa, os estudantes receberam informações a respeito da importância da educação ambiental, histórias do surgimento do sabão através da gordura, prejuízos que o descarte incorreto de óleos provoca ao meio ambiente, definição e importância da reciclagem e noções de segurança no momento de confeccionar o material. Utilizou-se como recursos didáticos: data show, caixa de som, quadro branco, pincel e vídeos educativos. 
Na segunda etapa realizou-se a confecção do sabão ecológico. Para tal foi utilizado: água, álcool, óleo de cozinha pós-uso, soda cáustica e sabão em pó; além dos materiais de apoio, como luvas de proteção, balde e bastão de madeira. O procedimento consistiu em adicionar ao balde soda caustica e água, mexer bem, em seguida acrescentar óleo, álcool e sabão em pó e mexer constantemente por 40 minutos (HAMMES \& RACHWAL, 2012). Depois de pronto, foi distribuído em frascos ou em garrafa pets e entregue aos alunos que levaram para casa.
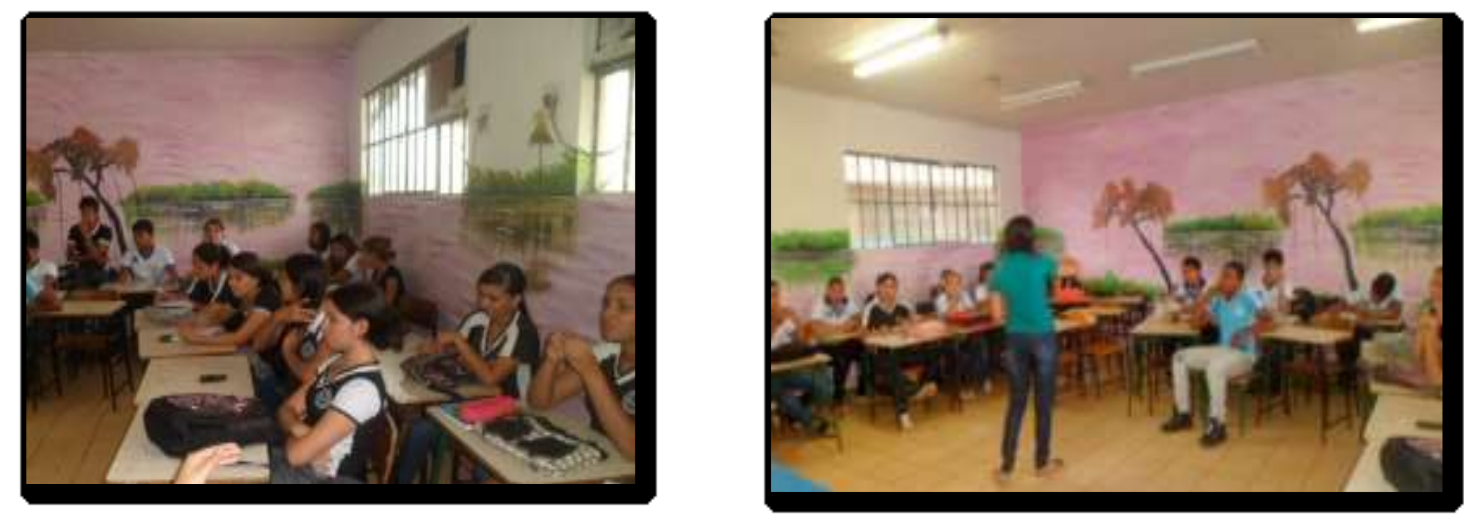

Figura 1. A e B: Palestras
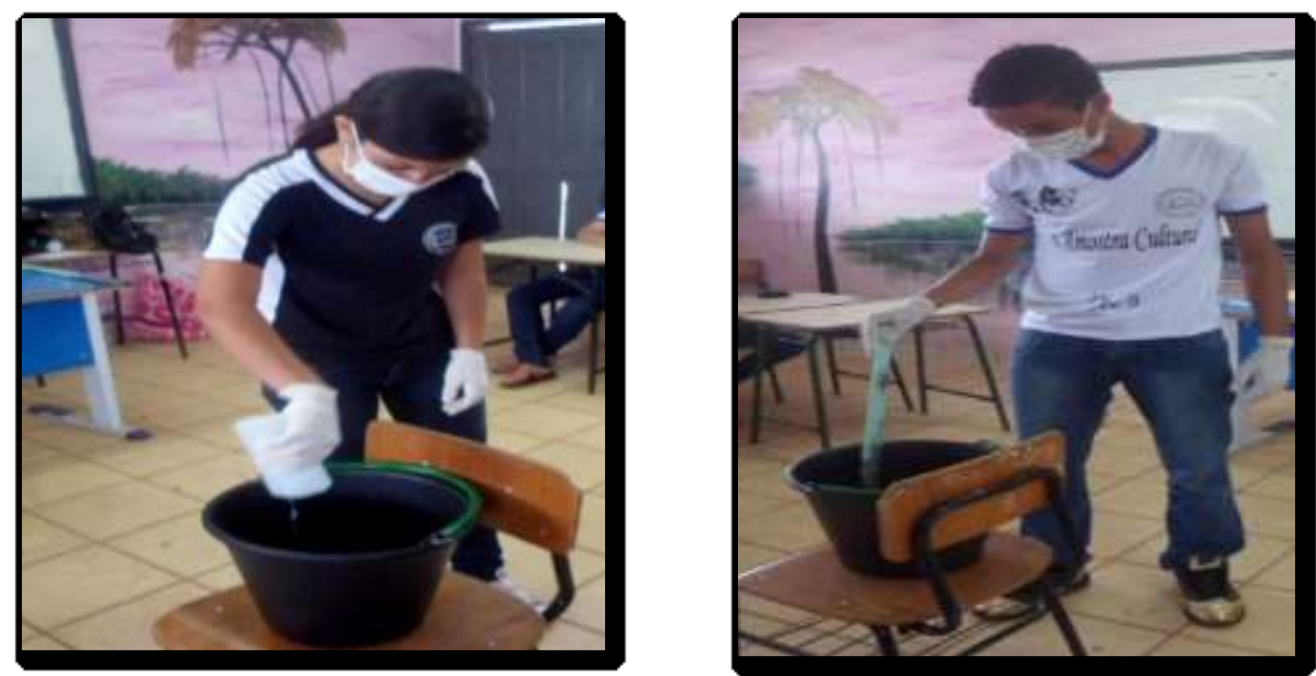

Figura 2. C e D: Produção do sabão ecológico.

\section{RESULTADOS E DISCUSSÕES}

No decorrer das palestras, percebeu-se grande interesse por parte dos alunos a respeito dos danos que o óleo causa ao meio ambiente, despertando um senso investigativo em relação aos meios ideais de descarte desse produto e um entusiasmo para aprender e produzir o sabão ecológico. Na segunda etapa, os alunos colocaram em prática o que foi compreendido na primeira etapa, participando efetivamente da produção do sabão. Esse estudo científico mostra como pequenas ações podem refletir positivamente no meio ambiente e no desenvolvimento de novas tecnologias economicamente viáveis e socialmente justas.

Para Azevedo (2009), o desenvolvimento de um processo de reciclagem de materiais depende de uma construção educacional, em que o currículo focaliza a formação de cidadãos socialmente responsáveis com conhecimento científico estruturado, possibilitando a compreensão da necessidade de se desenvolver políticas de desenvolvimento econômico e preservação ambiental.

É importante mencionar que o sabão produzido através da reciclagem do óleo "mostra-se eficiente, apresentando poder de detergência e uma boa formação de espuma, o que mostra a viabili- 
dade do mesmo em uso doméstico. Isso proporciona economia doméstica e diminuição dos impactos ambientais" (SILVA et al., 2010). O sabão também possui uma "boa degradação no meio ambiente, não ultrapassando mais que um dia para se decompor, assim, caso descartado em esgoto não trará tantos problemas para a natureza quanto o óleo residual" (ROCHA, 2014).

Assim, uma das alternativas para minimizar os impactos ambientais, causados pelo descarte incorreto do óleo, é a reciclagem desse resíduo através da fabricação de sabão artesanal, produto biodegradável, de fácil produção e de baixo custo, gerando economia com a diminuição do consumo de produtos de limpeza industrializados, além de ser um complemento financeiro a muitas famílias de baixa renda (SOARES; PUPO; MOURÃO, 2013). Essa alternativa é uma forma de agregar valor econômico, promover inclusão social e senso ecológico. Azevedo, et al (2009) e Silva, et al (2008) reportam que o sabão produzido pode ser utilizado no cotidiano por ser de fácil execução, e devendo ser disseminado pela comunidade, o que diminui a contaminação ambiental por esse resíduo.

Não podemos mais ter uma relação com a natureza de meros expectadores; somos parte integrante da natureza e temos o dever de minimizar impactos e buscar alternativas de melhoria de condições de vida. Este projeto mostra como pequenas ações podem refletir positivamente na preservação do meio ambiente e no desenvolvimento de novas tecnologias. (ALBERICI \& PONTES, 2004).

Ao término do projeto, percebemos a importância deste para a interação e conscientização ambiental, pois, apesar de a mídia evidenciar a preservação do ambiente, muitas vezes falta a prática. É preciso que o poder público, em conjunto com a sociedade organizada, comece a agir e saia da teoria para a prática, executando ações concretas em defesa do meio ambiente. A escola tem a responsabilidade de sensibilizar os alunos, que são multiplicadores das informações em suas casas, ou seja, eles juntos com seus familiares poderão agir e mobilizar a sociedade em defesa do meio ambiente (HAMMES \& RACHWAL, 2012).

Donaire (2008) destaca as oportunidades, sendo a reciclagem de materiais o que poderá trazer uma boa economia de recursos para as empresas; o reaproveitamento dos resíduos internamente ou sua venda para outras empresas, o desenvolvimento de novos processos produtivos com a utilização de tecnologias mais limpas para o meio ambiente, desenvolvimento de novos produtos para um mercado cada vez maior de consumidores conscientes com a questão ambiental, e tantos outros.

\section{CONCLUSÃO}

Ao final do projeto, ficou evidente que as atividades que envolvem a questão ambiental são de grande importância para o desenvolvimento dentro da escola. Práticas pedagógicas diferenciadas que permitem novos olhares, horizontes e mundos, possibilitando ampliar o conhecimento, tanto da comunidade escolar quanto dos educadores. Assim, o cerne deste projeto possibilitou integrar teoria e prática.

Espera-se que essa iniciativa pedagógica tenha despertado, não só nos alunos, mas em toda a comunidade escolar, a consciência da preservação da natureza e a disseminação dos conhecimentos adquiridos, contribuindo através do reaproveitamento desse resíduo, não só para o meio ambiente, mas para qualidade de vida. Assim, pode-se produzir em suas próprias casas o sabão ecológico, reduzindo os custos desse tipo de material, além de gerar alternativa de emprego e renda familiar.

\section{AGRADECIMENTOS}

À Escola Estadual de Ensino Fundamental e Médio Flora Calheiros pela valiosa aceitação e contribuição do projeto, e à FAPEAM pela concessão de bolsa de pesquisa.

\section{REFERÊNCIAS}

ALAMINI, B.; BARBADO, N. Destinação correta para o óleo de fritura. In: SEMANA AMBIENTAL: ENCONTRO TÉCNICO-CIENTÍFICO, 5, Foz do Iguaçu, 2008. Resumos... Foz do Iguaçu: União Dinâmica de Faculdades Cataratas, 2008. p. 31. Disponível em: <http://www.udc.edu.br/5semanaambiental.pdf $>$ 
Acesso em: 05 de out. de 2012.

ALBERICI, R. M.; PONTES, F. F. F. de. Reciclagem de óleo comestível usado através da fabricação de sabão. Espírito Santo do Pinhal: Engenharia Ambiental - Centro Regional Universitário de Espírito Santo do Pinhal, v.1, n.1, p.073 -076, jan./dez., 2004.

AMBIENTE EM FOCO. Reciclar óleo de cozinha pode contribuir para diminuir aquecimento global. Disponível em: <www.ambienteemfoco.com.br>. Acesso em: 10 set. 2012.

AZEVEDO, O. A. et al. Fabricação de sabão a partir do óleo comestível residual: Conscientização e Educação Científica. XVIII Simpósio Nacional de Ensino de Física - SINEF 2009 - Vitória ES. Disponível em: <http:// www.sbf1.sbfisica.org.br/eventos/snef/xviii/sys/resumos/T0805.pdf> Acesso em: 09 set. 2012.

CARVALHO, K. M. DE. Responsabilidade ambiental na gestão pública. Disponível em: <http://www.seplag. rs.gov.br/upload/Painel_56_Kleberson_Martins_formatado.pdf> Acesso em: 10 set. 2012.

DONAIRE, Denis. Gestão Ambiental na Empresa. São Paulo. Atlas, 2008.

HAMMES, V.S.; RACHWAL, M.F.G. Educação Ambiental: Meio Ambiente e a escolar. Brasília, DF: Embrapa, 2012.

PORTO ALEGRE. Meio Ambiente. Disponível em: <www2.portoalegre.rs.gov.br> Acesso em: 12 set. 2012.

RABELO, R. A.; FERREIRA, O. M. Coleta Seletiva de óleo residual de fritura para aproveitamento industrial. Ambiente em Foco. Departamento de Engenharia-Engenharia Ambiental, Universidade Católica de Goiás-GO, 2008.

ROCHA, T. M.; SILVA, H. Avaliação da qualidade de sabão produzido a partir da reciclagem de óleo comestível, baseado no volume de espuma formado. Disponível em: <http://www.ebah.com.br/content/ABAAABTooAD/avaliacao-qualidade-sabao-produzido-a-partir-reciclagem-oleo-comestivel> Acesso em: 13 jun. 2014.

SABESP. Companhia de Saneamento Básico do Estado de São Paulo. Reciclagem de Óleo (PROL) 2011.

SILVA, J.S. et al. Produção de sabão a partir de resíduos de óleos vegetais. In: CBQ 50 CONGRESSO BRASILEIRO DE QUIMICA, 2010. Disponível em: <http://www.abq.org.br/cbq/2010/trabalhos/4/4-226-8356. htm> CUIABA-MT. Acesso em: 11 set. 2012;

SILVA, A. M. S., et al. Oficina de Reciclagem de Óleo de Fritura como Ação Integradora de Estudantes de Licenciatura em Química no Ambiente Escolar. R. P. Química Nova, p.31, 2008.

SOARES, V. DA S.; PUPO, D. D.; MOURÃO, R; DE C. Produção de sabão artesanal no município de sorriso - MT: alternativa sustentável ao óleo usado. IBEAS - Instituto Brasileiro de Estudos Ambientais. In: IV CONGRESSO BRASILEIRO DE GESTÃO AMBIENTAL, Salvador/BA, 2013. Disponível em: < http://www. ibeas.org.br/congresso/Trabalhos2013/III-035.pdf.> Acesso em: 15 jun. 2014. 